\title{
Current and future challenges for better water supply sustainability in northern part of Iraq
}

\author{
Tahir Shamsalddin Abdalsamad ${ }^{1,{ }^{*}}$, Youssef Kassem ${ }^{2}$ and Hüseyin Gökçekuş ${ }^{3}$ \\ ${ }^{1}$ Department of civil and environmental, Faculty of Engineering, near east university, (via Mersin 10, Turkey), Nicosia, \\ Cyprus. \\ 2 Department of Mechanical Engineering, Engineering Faculty, Near East University, (via Mersin 10, Turkey), Nicosia, \\ Cyprus. \\ ${ }^{3}$ Department of Civil Engineering, Civil and Environmental Engineering Faculty, Near East University, (via Mersin 10, \\ Turkey), Nicosia, Cyprus.
}

World Journal of Advanced Engineering Technology and Sciences, 2022, 05(01), 055-062

Publication history: Received on 19 December 2021; revised on 12 February 2022; accepted on 14 February 2022

Article DOI: https://doi.org/10.30574/wjaets.2022.5.1.0079

\begin{abstract}
Water supply sustainability is related to our daily life and a very important issue and related for every people around the north part of Iraq. The NPI's water resources are in jeopardy. Climate change is evident in the region, and it is predicted to reduce output. The Tigris River and its tributaries, the Greater and Little Zab Rivers, as well as the Sirwan River. Extreme weather has afflicted the NPI over the last decade, ranging from droughts to torrential rainfall. For decades, water infrastructure has been neglected, environmental standards protecting water quality have been ignored, and water has been squandered due to overconsumption. In addition, the NPI's neighbours Turkey and Iran have been building a slew of dams on rivers that the NPI relies on. Some of these have the potential to have a significant impact on the Tigris flow into NPI. The water discharge of the Tigris-Euphrates Rivers is expected to drop by half in the next decade, according to the UNDP. The KRG's strategic goal is to build a significant number of dams across its territory, with the goal of storing water for irrigation and hydroelectric generation, to combat climate change, upstream dam construction, and mismanagement. Annual income for water in NPI is 28 billion meter cube but more than 20 billion meter cube was waste without benefit for water supply in general (95\%) of this water was discharge without any using in for agricultural, industrial sector and domestic water supply. About the water production rate fee in NPI by Kurdistan region government (KRG) for water supply around (57400 \$) every day. Water production for one day is (1.874 Million meter cubic per day) and (70 Million meters cubic per month). All of the people are responsible on their site for using water on preserving it in the rate in the region they leaving because it fact other regions.
\end{abstract}

Keywords: Challenges; Water supply sustainability; Northern part of Iraq; Water production

\section{Introduction}

\subsection{Challenges for better water supply sustainability}

In general, there is a lot of challenges (current and future) in front of the north part of Iraq (NPI) that should be evaluated and desiccation and researched and get a good result by the scientific way for the challenges because the water supply sustainability is related to our daily lives and very important issue and related for every people around the north part of Iraq. Also, some of the challenges are from a governmental issue like (no exact plan, no enough budget for doing good project). And some of the challenges are related to people wasting more water in their daily life. Also, neighbouring

\footnotetext{
* Corresponding author: Tahir Shamsalddin Abdalsamad; Email: tahir91rania@gmail.com

Department of civil and environmental, Faculty of Engineering, near east university, Nicosia, Cyprus. 
countries are a negative effect on water supply sustainability like (Turkey, Iran), because the main water sources are in there then come to NPI. And climate change is another barrier to better water supply sustainability in NPI.

\subsection{Northern Part of Iraq (NPI)}

Iraq, officially known as the Republic of Iraq, is a country in Western Asia bordering on the north by Turkey, the east by Iran, the southeast by Kuwait, the south by Saudi Arabia, the southwest by Jordan, and the west by Syria. The northern part of Iraq (NPI) is also called the Kurdistan region of Iraq (KRI) is a self-governing region in Iraq and located in the North of Iraq that is situated in the Middle East, it consists of four governorates, Erbil, Sulaymaniyah, Duhok and Halabja, also Population of Northern part of Iraq is around 6.2 million people in 2020, but current statistics are not available in government, The population of NPI is predicted to grow by 137,000 people per year, with a normal growth rate of 2.5 percent. By 2060, the population of NPI is expected to reach 15.32 million people. NPI has a total area of 40,643 square kilometres, which is larger than the Netherlands and four times the size of Lebanon [1]. Mountains dominate the north and north-east, whereas planes dominate the south and southwest. In the summer, the weather in the northern region of Iraq is semi-arid, dry, and extremely hot, and damp and freezing in the winter. In the northern section of Iraq, the average temperature ranges from almost $\left(13.5^{\circ} \mathrm{C}\right)$ in Penjuen to $\left(21.56^{\circ} \mathrm{C}\right)$ in Erbil [2]. The average annual rainfall in the NPI is 633 millimetres per year, which increases in mountain areas to 1308 millimetres per year in Mergasor in the north of the NPI and 157 millimetres per year in Taqtaq in the flat area [3]. Iran is on the northeastern border, Turkey is on the north, Syria is on the northwest, and Iraq is on the south. The Mosul Dam, Dokan Dam, and Darbandikhan Dam are all located within the NPI zone. The northern portions of NPI are mountainous, with peaks reaching up to 3600 meters above sea level, while the southern parts consist of plains appropriate for grain production [4]. Orographic precipitation from the mountains governs the climate of NPI, resulting in high precipitation rates in the north and clotheshorse weather on the plains. Weather in the area [5]. Rainfall in NPI is measured from October to May, with little or no rainfall during the hotter summer months. The annual rainfall averages between 300 and $1000 \mathrm{~mm}$, with yearly variations ranging from 100 to $1300 \mathrm{~mm}[6,7]$. The average temperature in the winter is around $5{ }^{\circ} \mathrm{C}$, while in the summer, the average temperature is around $30^{\circ} \mathrm{C}$, though it can occasionally exceed $50{ }^{\circ} \mathrm{C}$ in the southern portions [8]. Wheat is the largest prevalent crop in the NPI landscape, accounting for around 16.5 percent of the entire NPI area in 2011 [9]. Iraq receives the most percentage of annual precipitation from NPI. The high mountain ranges in NPI's east and north-eastern regions aid in the collection of clouds and precipitation for growth. Snow and rainfall in late autumn and early spring, enlarging the region's water resource to the point that, if properly gathered, NPI can be water-sufficient without relying on river flows from the adjacent country, and Iraq as a whole will benefit. However, NPI's water usage training is not long-term; rainwater is largely uncollected; groundwater and surface water are overly and irrationally exploited in large areas, and they are missed and contaminated in large quantities [10]. The Kurdistan Regional Government (KRG) is the official name for NPI's government, which has a parliament, laws, and instructions governing water resources, both groundwater and surface water. However, regulations must advance further to adequately state all significant phases of water concerning sustainability, and they must be well implemented on the ground; the existing training of water usage is destructive to future water availability and present, in both quality and quantity, in NPI [11]. Unsustainable water use exposes NPI to a variety of risks now and in the future. The demand for water in NPI has increased since the country's economic boom began in the early 2000s, a process that has resulted in the growth of metropolitan centres as well as industrial and agricultural activity. In NPI, the terrain is mostly mountainous, with a few fertile plains in between [12]. Large portions of NPI are reliant on rivers from Iran and Turkey; yet, NPI has its own water resources, which are underdeveloped and underutilized [13].

\subsection{Water supply sustainability in Iraq}

Sustainable water supply refers to the development of dependable and resilient solutions to varied human water needs that do not deplete local water supplies or have a long-term detrimental impact on the environment. Agriculture consumes over $70 \%$ of the world's current water supply, while industrial and home use accounts for $22 \%$ and $8 \%$, respectively. The focus of this research is on the domestic water supply. Groundwater, surface water, and rainwater collection are the most common sources of potable water for home use (RWH). Other options include fog or air moisture harvesting, bottled water, or even melting snow or ice, as well as seawater desalination. Desalination of seawater procedures have progressed, but they still require a significant amount of energy and are hence not self-sustainable. This study will focus on groundwater and surface water sources, as well as RWH, as well as other knowledge that aids in the range and design of sustainable water supply options in various parts of the world, including crises. Case studies are used to explain various water supply and treatment options and to foster knowledge growth [14]. Sustainable improvement has been generally helped in Iraq as a holistic perception which goals or objectives to participating social, economic and cultural policies to certify high-quality evolution. However, there are a lot of barriers to combating the application of sustainable improvement. The chief barrier to attaining sustainable expansion is the lack of a human vision of the current and the future. In Iraq, political and economic systems are intended to understand just what is very close to our hands and our eyes. There is no concern, from part of the instituting, in expenditure energy in thinking 
about the current and future of the human being. Economic improvement is oriented to make extra regulars, more debtors more singular pushing the economy to develop. The planetary significances of abandoned progress stay out of any political or economic analysis.

\subsection{Water supply}

Water is essential for economic development, healthy ecosystems, and human existence, and it is at the centre of longterm progress. It is critical for lowering the global burden of disease and improving population health, welfare, and efficiency. It is necessary for the creation and maintenance of a wide range of services and benefits for people. Water also plays a role in climate change adaptation, serving as a vital link between human society, the climate system, and the environment [15]. In many places of the world, where water availability has become a persistent issue, the previous few decades have shown new hurdles for promising water delivery [16]. The distribution of water by public utilities, commercial companies, or individuals, usually through a system of pipes and pumps, is known as water supply. The consistency of supply water pressure and the quality of the water are two characteristics of service quality.

\section{Research methodology}

This study aims to improve the water supply sustainability in the Northern part of Iraq Because there are a lot of problems in the water sector and there is not enough water for drinking and agriculture and industrial, in general, some of the areas has water crisis so that it needs to obtain the real data and analyses it to better water supply sustainability plan. And get some recommendation for government and people to good results for future. The design of the study is showing the description of some strong points like (how to save water and how to get water from sources) and weak points like (how to take away the barriers) to make a good plan and get important strategy and how to solve the water supply problems that will be challenged and make comparative in the system and projected between NPI water supply and developing country for water supply and also analyzing the data like how much water needs for people in the study area NPI as it showed in (Figure 1) and how much water have in this area and how is the good water management system.

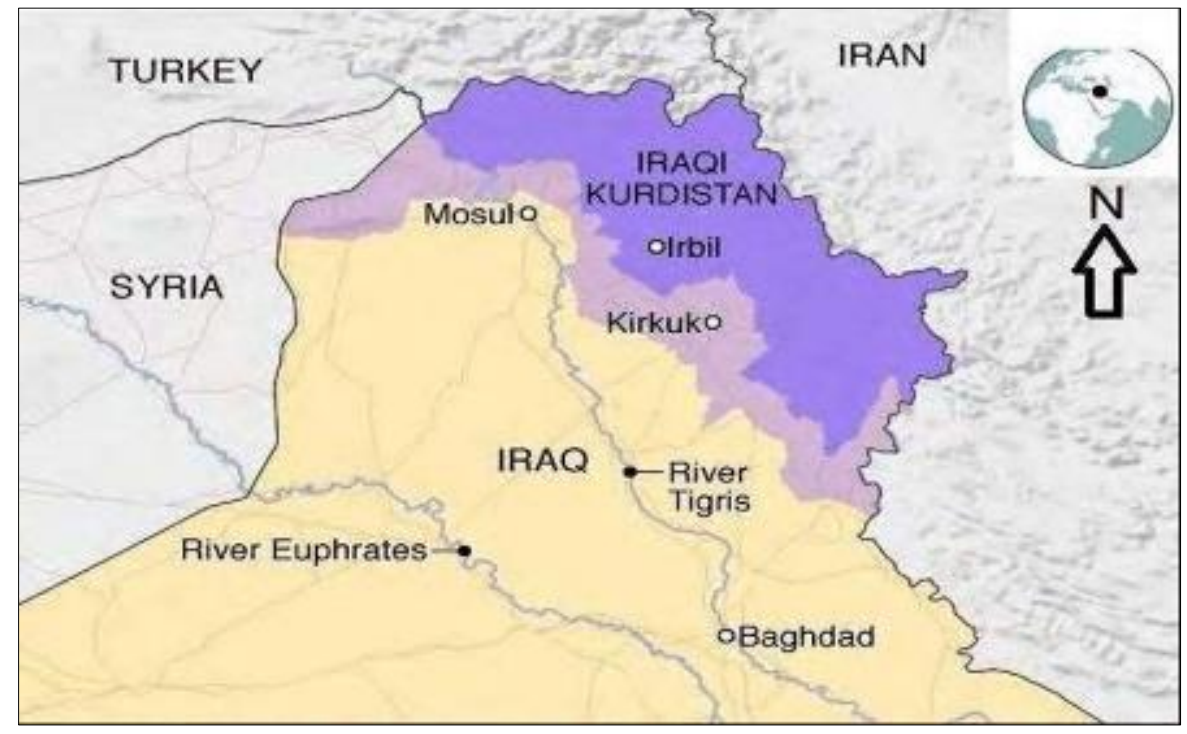

Figure 1 Adapted from a map of the Northern part of Iraq

This study examines the notion of water sustainability and establishes UNICEF water sustainability criteria for NPIs. It examines some examples of water consumption in NPI in various sectors and assesses them in terms of sustainability. It then examines the laws and regulations that the (KRG) has enacted on water and water-related issues, identifying difficulties with relation to sustainability; sustainability as a principle is intended to be reflected in a nation's environmental laws and policies [13]. 


\section{Results and discussion}

\subsection{Water production}

If focused in NPI in addition to having many water resources but because of there is not required dams and also there is no having good lows for a water management system, these resources do not use in a good way to produce water and a lot of water throw out without using, also it is one future challenge in this sector. About the water production rate fee in NPI by Kurdistan region government (KRG) for water supply around (57400\$) every day. Water production in for one day is (1.874 Million meter cubic per day) and (70 Million meter cubic per month) and water production in NPI according to the governorates in Erbil is 962000 meter cubic per day and Sulaymaniyah is 579000 meter cubic per day and in Duhok is 410000 meter cubic per day and in Halabja is 119000 meter cubic per day, as it is mention in the (Figure 2). All data manually is received from the government.

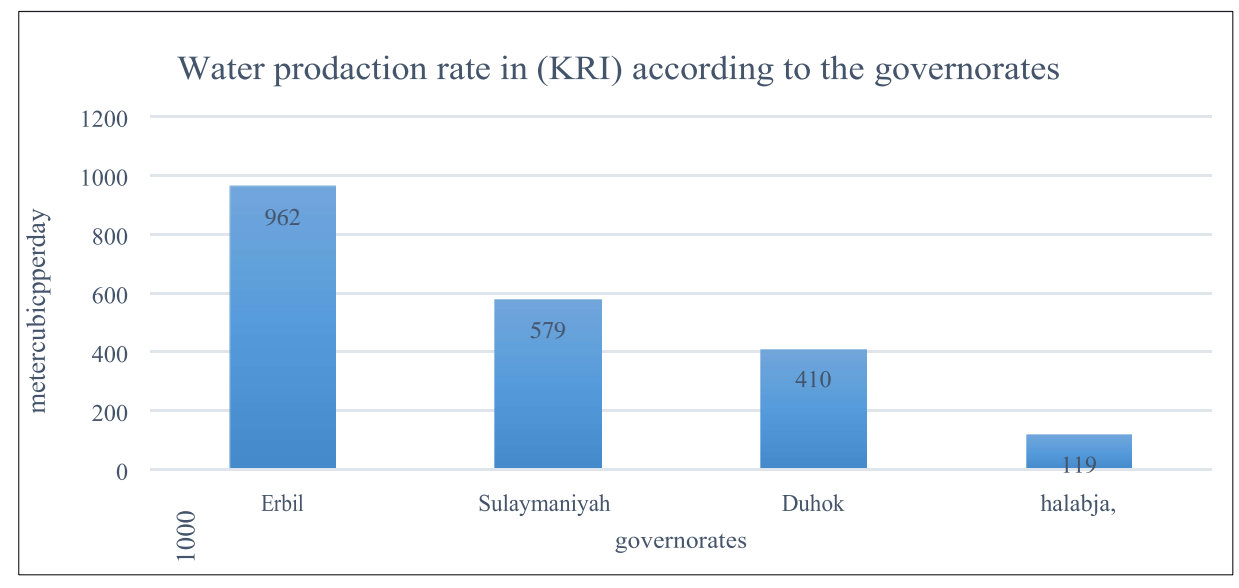

Figure 2 Water production in (NPI) according to the governorates

\subsection{Wastewater in NPI}

If see NPI there this a lot of waste of water by people it increased the rate of water production over the government, everyday 900000-meter cube wastewater that is production rate equal 230000\$. UNICEF standard for using water is 302.8-378.5 Litres per day, this criterion for managing wastewater and low using water in the day and for making the water is a distribution for people in the world. Little Zab river is one of the important rivers in surface water for water security in NPI and it will be a good way to improve water supply for NPI and also for other parts of Iraq if the strategic project will be created on it .length of Little Zab is approximately $402 \mathrm{KM}$ [17], annual income of the river is around 12 billion meter cube but in this river annual outcome is around 10 billion meter cube, it means (95\%) of this water was discharged, in one second the rate of the wastewater is around a 294-meter cube. On this river until now just two projects were created, one of these projects is irrigation agriculture and one of the projects is domestic water supply. In general annual income for water in NPI is 28 billion meter cube but more than 20 billion meter cube was waste without benefit for water supply. If we compare to another developed country like the United Arab Emirates just water production and invested only by one billion meter cube for all water security and food production for people.

\subsection{Water resources in NPI}

\subsubsection{Rainfall}

Rainfall is one of the most important climate events, and it can alter dramatically in a short amount of time [18]. Due to a variety of influences and changing climate conditions, annual rainfall varies from year to year and season to season. [19]. Figure 3 shows that the different rainfall rates from 2012 to 2020 over millimetres [20]. And according to the data the rainfall rate is different from year to year is some of the factors that have been affected by rainfall rates such as claimant change and seawater level and temperature change. If the rainfall rate is low also the water ground level will decrease and the water level of the dam will be low and the water of the river will be low but if the rainfall rate is higher, all of them will increase. Also, the rainfall rate is affecting the water supply sustainability. 


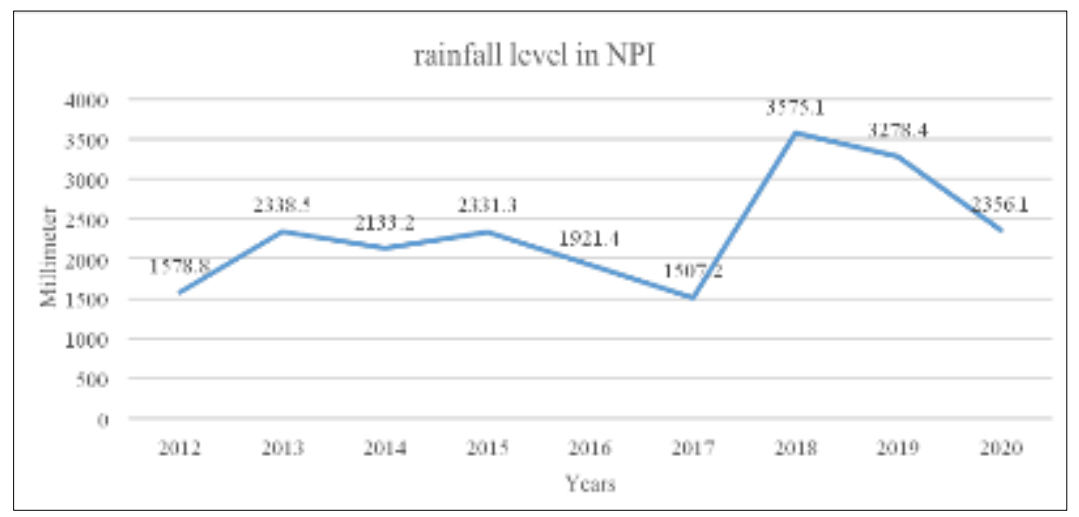

Figure 3 Rainfall level in Kurdistan region for the year's 2012-2020/mm

\subsubsection{Groundwater (GW)}

Most of the groundwater sources are located in the northeast of NPI and there has a good water quality because the nature (freshwater) and topography of this area is good. Groundwater sustainability refers to the process of improving and using groundwater in a way that may be continued indefinitely without producing unacceptable environmental, economic, or social consequences. [21]. Groundwater is measured as a strategic resource of water due to its natural great quality and continual obtainability. However, the sustainable management of $(\mathrm{GW})$ characterizes a vital business all over the world [22]. In one day 468000 meters of cubic used groundwater in NPI.

\subsubsection{Tigris and Euphrates}

The Tigris and Euphrates Rivers are the two major rivers that historically fed Mesopotamia's Fertile Crescent, which stretches into modern-day Turkey, Iran, Syria, and Iraq as shown in Figure 4. The zone was home to the first well-known human settlements. Agriculture was very important in Mesopotamian communities, and it dates back to 8000 B.C. Because of the dry environment in the area, agriculture is reliant on the Tigris-Euphrates Rivers flooding for soil availability. The Tigris rises in the mountains of eastern Turkey and flows through the highlands of Turkey's NPI, These two rivers form a transboundary basin with an overall area of $879,790 \mathrm{~km}^{2}$. The Tigris travels through the valleys of NPI's plateau before descending into the parched plain of Mesopotamia after skirting the Syrian-Turkish border for less than 45 kilometres. In southern Iraq, near Qurna, the Tigris joins the Euphrates in the Shatt Al-Arab, which empties into the Persian Gulf. The Tigris continues to be a source of water for agriculture and freshwater for Mesopotamia's indigenous inhabitants. Irrigation is commonly used to help crops grow. The population of Central and Southern Iraq is nearly exclusively reliant on the Tigris-Euphrates Rivers [23].

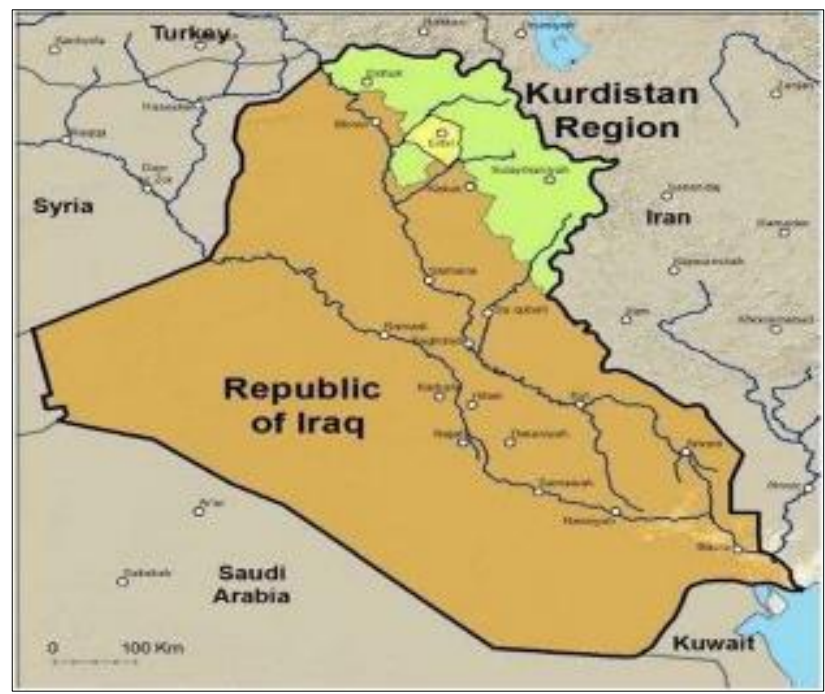

Figure 4 Iraqi map with the Kurdistan Region in the north (green). (Source unknown) 


\subsection{Dams in NPI}

Since 2014, the KRG has proposed 245 dams, in addition to 17 big and moderate existing dams. This would mean that no river in the NPI would be unaffected. Dams have been lauded for their social and economic benefits, but they come at a tremendous cost to humanity and the environment. Dam projects, according to proponents, are a safe method to meet energy and agricultural demands. There is little or no discussion in the NPI regarding the dams' negative effects on free-flowing rivers, biodiversity, water quality, cultural heritage, people's livelihoods and houses, and the water security of Federal Iraq downstream. The Greater and Little Zab Rivers, which pass through the NPI, account for half of the Tigris river flow in Baghdad. These waters are vital to the Iraqi Marshes, Asia's largest wetlands. Dams degrade water quality and devastate riverine habitats, which are vital to plants and animals. Dams also result in population displacement as well as the destruction of prime agricultural fields and cultural artefacts that are submerged beneath dam reservoirs. Many cases of dam failure can be found in the NPI. There are numerous examples of faulty dam infrastructure around the NPI. For the Tigris River, basin-wide comprehensive water policies must be devised, giving experts and decision-makers the tools they need to better water management in the region. There would be no need to dam all of the country's rivers if the NPI could develop a vision for water security that included collaboration among many institutions and appropriate water resource management. Free-flowing rivers, on the other hand, would be highly prized for their biological, aesthetic, recreational, and cultural assets.

\subsection{Water management system}

Water management is a system and program for managing water resources in order to reduce harm to people and property while increasing well-organized beneficial use. Dams and levees with good water control reduce the risk of flooding damage. Irrigation water management structures make the best use of limited agricultural water supply.

\subsection{Comparative between NPI and United Arab Emirates (UAE)}

If we compared NPI to UAE, it is illuminating to the total area of UAE is bigger than NPI but the annual water usage is less than NPI because in UAE wastewater is under control by having a good water management system and by particularizing high budget for water production, Wastewater in NPI should be treated by people and government. However, in USE there is no river to get water to production but government try to get water for people from sea and groundwater but in NPI have two big rivers and surface water is available to get water supply easily. Annual rainfall in NPI is higher than UAE it is also an advantage for NPI to water supply sustainable, as it is shown in table 1 clearly [24], [25].

Table 1 Summary of total area, population growth, water usage, water production cost, number of rivers and rainfall of UAE and Iraq (NPI)

\begin{tabular}{|c|l|l|l|l|l|l|}
\hline Country & Total area & $\begin{array}{l}\text { Population growth } \\
\text { rate (\%/year) }\end{array}$ & $\begin{array}{l}\text { Annual } \\
\text { water } \\
\text { usage }\end{array}$ & $\begin{array}{l}\text { Water } \\
\text { production } \\
\text { cost (USD) }\end{array}$ & $\begin{array}{l}\text { Number } \\
\text { of river }\end{array}$ & $\begin{array}{l}\text { Annual } \\
\text { Rainfall }\end{array}$ \\
\hline $\mathrm{UAE}$ & $172,494 \mathrm{~km}^{2}$ & $2.71 \%$ & $1.6 \mathrm{Bm}^{3}$ & $\$ 2.48 / \mathrm{m}^{3}$ & 0 & $78 \mathrm{~mm}$ \\
\hline $\begin{array}{c}\text { Iraq } \\
\text { (NPI) }\end{array}$ & $40,643 \mathrm{~km}^{2}$ & $2.5 \%$ & $8 \mathrm{Bm}^{3}$ & $\$ 0.03 / \mathrm{m}^{3}$ & 2 rivers & $300-1000 \mathrm{~mm}$ \\
\hline
\end{tabular}

There is no big gap between NPI and UAE in the sector of agriculture and industry and domestic as shown below in Table 2 clearly [26].

Table 2 Distributions of water used by sector in UAE and Iraq (NPI)

\begin{tabular}{|l|c|c|c|}
\hline Country & Domestic & Industry & Agriculture \\
\hline UAE & $24 \%$ & $10 \%$ & $67 \%$ \\
\hline Iraq (NPI) & $8 \%$ & $22 \%$ & $70 \%$ \\
\hline
\end{tabular}




\section{Conclusion}

Water is one of the most necessary parts of daily life not just for people for animals and plants and everything [27]. In NPI all precursors allude to abundance in upper groundwater, but pertinent Government authorities do not do much concerning water projects, however, small and medium-size dams are essential in addressing and conserving water security at the same time in the study area. In my opinion, the main part for better water supply sustainability is:

- It's necessary to consider water management because water management is important, if there is a lot of water but there is not good managing water by the suitable way this time the menace will be higher.

- $\quad$ The near future must make a plan and do the strategic projects for aggregation of irrigation and agriculture and provide water for people of all the places that suffered for storage of water.

- The government in the highest please must contact the neighbour country for the river water resources that in the neighbour country, and it must be good incoming amount of water and also according to international law that it is described water resource exploded water it's for all the humanity necessary ranger.

- The government under parliament must issue a new regulation reduction of water wastage what is the range common standard and punishment those how those who not follow the law and regulation.

- As well as the media (TV, radio, newspaper and so on) must take it all in one in society toward deserving water, on water reserve and security in the region that the water is a national treasury for everyone to take care and deserve it.

- In the Education sector, it's very important that educate the next generation, not to wastewater and preserve in it and for sustaining life.

- $\quad$ all celestial religion to the special account of water as well as a religious leader that they can take an important role on coming awareness conserving water and on preserve in water security in NPI in religions aspect. Because most people commit it to religion and they respected it.

- All of the people are responsible on their site for using water on preserving it in the rate in the region they leaving because its fact other regions.

- Climate change in all of the world alerted that it needs an urgent solution for water supply if not the situation will face great danger in the near future.

- $\quad$ And groundwater will be safe and do not use until the surface water will be at the lowest level.

\section{Compliance with ethical standards}

\section{Acknowledgments}

I acknowledge my co-authors for their support throughout this research.

\section{References}

[1] Kurdistan Regional Statistics Office KRSO. Population of KRI 2009-2020: Department of Planning, Special Report. 2014.

[2] Hawrami KS, Shareef AJ. Turkish Virtual River in Kurdistan Region Iraq. European Online Journal of Natural and Social Sciences. 2020; 9(3): 545.

[3] Eklund L, Persson A, Pilesjö P. Cropland changes in times of conflict, reconstruction, and economic development in Iraqi Kurdistan. Ambio. 2016; 45(1): 78-88.

[4] Eklund L, Seaquist J. Meteorological, agricultural and socioeconomic drought in the Duhok Governorate, Iraqi Kurdistan. Natural Hazards. 2015; 76(1): 421-441.

[5] Eklund L, Abdi A, Islar M. From producers to consumers: the challenges and opportunities of agricultural development in Iraqi Kurdistan. Land. 2017; 6(2): 44.

[6] Hijmans RJ, Cameron S, Parra J, Jones P, Jarvis A, Richardson K. World clim Global Climate Data. 2021.

[7] Kurdistan Region Statistics Office (KRSO). Agricultural Areas in the Governorates of Kurdistan Region; Kurdistan Region Statistics Office: Erbil, Iraq. 2012.

[8] Abdulrahman SA. Water shortage in GCC countries: Transferring water from Iraqi Kurdistan Region. International Journal of Environmental Studies. 2020; 77(2): 191-207. 
[9] Abdulrahman SA. Water use Practice and Water Law in Kurdistan Region: How can Sustainability be achieved? Environmental Policy and Law, (Preprint). 1-11.

[10] Kurdistan Regional Government. 2017.

[11] Beder S. Environmental Principles and Policies, UNSW Press, China. 2006.

[12] WBCSD. Facts and Trends. Water (Version 2). Geneva: World Business Council for Sustainable Development (WBDSC) URL. 2009.

[13] A. A. Hussain, F. Al-Turjman, Artificial intelligence and blockchain: A review. Transactions on Emerging Telecommunications Technologies (2021). 10.1002/ett.4268.

[14] Bardini MD. The water policy reform program of the economic development institute: tracer evaluation report. 1998.

[15] Waterkeepers Alliance - Iraq, "Lesser Zab Threat Assessment \& Action Plan (TAAP) Report.

[16] Dizayee RH. Groundwater Degradation and Sustainability of the Erbil Basin, Erbil, Kurdistan Region, Iraq. Texas Christian University, Fortworth, Texas. 2014.

[17] Hameed H. Water harvesting in Erbil Governorate, Kurdistan region, Iraq: detection of suitable sites using geographic information system and remote sensing. Student thesis series INES. 2013.

[18] Weather Statistics in Kurdistan Region Governorates for the years 2020-2012.

[19] Alley WM, Reilly TE, Franke OL. Sustainability of ground-water resources (Vol. 1186). US Department of the Interior, US Geological Survey. 1999.

[20] Mawlood DK. Sustainability of Aquifer and Ground Water Condition in Erbil Basin/Iraq.

[21] A.A. Hussain, B. Dawood, F. Al-Turjman (2021). Application of AI Techniques for COVID-19 in IoT and Big Data Era: A Survey. 10.1007/978-3-030-60188-1_9.

[22] Food and Agriculture Organization (FAO). Irrigation in the Middle East Region in Figures AQUASTAT Survey 2008.

[23] Schwab, K. (2016), "The fourth industrial revolution: what it means, how to respond", Retrieved 4 October 2018, From World Economic Forum - Global Agenda website, [Online] Available: www.weforum.org/agenda/2016/01/the-fourth-industrialrevolution-what-it-means-and-how-to-respond/.

[24] Saif 0, Mezher T, Arafat HA. Water security in the GCC countries: Challenges and opportunities. Journal of Environmental Studies and Sciences. 2014; 4(4): 329-346.

[25] Murad AA, Al Nuaimi H, Al Hammadi M. Comprehensive assessment of water resources in the United Arab Emirates (UAE). Water Resources Management. 2007; 21(9): 1449-1463. 